\title{
Reproducción y lucha de clases. Bosquejo de una lectura althusseriana del neoliberalismo
}

\section{Reproduction and Class Struggle. Outline of an Althusserian Reading of Neoliberalism}

\author{
Gisela Catanzaro \\ CONICET-Instituto Gino Germani, Argentina \\ giselacatanzaro@yahoo.com
}

Natalia Romé Universidad de Buenos Aires, Argentina romenatalia@yahoo.com

Resumen: A partir de un breve recorrido por tres perspectivas importantes para el abordaje crítico del llamado "neoliberalismo", el artículo identifica una vacancia común en su caracterización como momento pos-hegemónico del capitalismo, como racionalidad de gobierno de las subjetividades o como articulación hegemónica. En todos los casos se trata de análisis que, basándose en la detección de un rasgo de la formación social neoliberal -la lógica del Capital, del Poder, o de las articulaciones políticas-, encuentran serias dificultades para pensar su inscripción en la complejidad sobredeterminada de la totalidad histórica. A partir de esa lectura, se propone una revisita de la Teoría de la Reproducción Social formulada por Louis Althusser hacia fines de los años sesenta, y se pone el foco en la pregunta por el complejo de relaciones, tendencias 
y tensiones que le confieren su consistencia contradictoria y su historicidad heterogénea a una formación social. Este proceder da lugar a la intelección de procesos estructurales de larga duración, pero a través de los rodeos imprescindibles por los aspectos concretos en que esas tendencias existen y sin los cuales sus determinaciones económicas devienen abstractas: la coyuntura ideológica entendida como el complejo de dispositivos, formaciones discursivas, prácticas y formas interpelativas que dan existencia concreta y a la vez modulan la duración/transformación de un orden dado de relaciones, y los procesos de subjetivación política de sus contradicciones, en su contingencia sobredeterminada. El abordaje propuesto permite caracterizar al neoliberalismo como un proceso coyuntural, inestable pero determinado. Con esta matriz teórica se bosquejan, finalmente, algunas conjeturas generales para comprender las circunstancias concretas de la coyuntura neoliberal argentina de los últimos años.

Palabras clave: neoliberalismo, Louis Althusser, reproducción social, sobredeterminación, ideología.

Abstract: Based on a brief review of three important perspectives for a critical approach to so-called "neo-liberalism", the study identifies a common vacancy in its characterization as a post-hegemonic capitalism; as a specific rationality; or as a hegemonic articulation. Despite their differences, these analyses are based on the detection of a single feature of the neoliberal social formation -the logic of Capital; Power or political articulations- and find extremely difficult to conceptualize its inscription in the overdetermined complexity of the historical totality. Based on this reading, a revision of the Theory of Social Reproduction formulated by Louis Althusser towards the end of the I960s is proposed, focusing on the question of the complex of relationships, tendencies and tensions that confer its contradictory consistency and heterogeneous historicity to a social formation. This allows the intellection of 
long-lasting structural processes, but through the essential detours of the concrete aspects in which these tendencies exist and without which their economic determinations become abstract: on the one hand, the ideological situation, understood as the complex of devices, discursive formations, practices and interpellation forms that give concrete existence and at the same time modulate the duration/transformation of a given order of relations; on the other hand, the processes of political subjectivation of its contradictions, in its overdetermined contingency. This approach allows us to characterize neo-liberalism as a conjunctural process, unstable but determined, and -finally- to sketch out some general conjectures in order to understand in a complex way the concrete circumstances of the Argentinean neoliberal situation in recent years.

Keywords: Neoliberalism, Louis Althusser, Social Reproduction, Overdetermination, Ideology.

Recibido: 9 de noviembre de 2020

Aceptado: 15 de diciembre de 2020 https://dx.doi.org/IO.I 5 I74/rv.vi 3i27.580

\section{Introducción}

$\mathrm{E}$ n una mirada panorámica a las aproximaciones críticas del mundo contemporáneo más relevantes y difundidas en la actualidad se destacan, esquemáticamente, tres perfiles teóricos enraizados en tradiciones de pensamiento diversas y a partir de las cuales lo neoliberal resulta caracterizado como un singular tipo de racionalidad, como una nueva hegemonía política o, bien, como un emergente pos-hegemónico de la recomposición de la explotación de clase bajo el capitalismo luego de la crisis económica de la década de 1970. Ninguna de estas perspectivas ha dejado de destacar los efectos des-democratizadores y potencialmente autoritarios 
del neoliberalismo, pero mientras en la primera el foco analítico de impronta foucaultiana recae en la eficacia de cierto gobierno de las prácticas signado por el imperativo de la auto-capitalización para la producción y reproducción de subjetividades normativas, la segunda ha enfatizado -en el marco de la tradición gramscianael papel de los antagonismos y luchas políticas en la configuración de una nueva hegemonía que se quiere "pos-política", y la tercera los efectos social y políticamente disolventes del despliegue desregulado de la lógica del capital, donde la explotación asumiría una renovada literalidad.

Estas constituyen perspectivas relevantes en una escena teórica e interpretativa cuya vitalidad, como veremos en el primer apartado, no parecería del todo ajena a una activa reinterpretación de los conceptos centrales de la tradición del pensamiento crítico materialista. Sin embargo, un discurso teórico o analítico, capaz de articular sus diversos énfasis en una pregunta por la totalidad compleja que los aloja, resuena hoy extrañamente anacrónico. Antes que en los conceptos considerados aisladamente, lo extemporáneo de una invocación a la reproducción, la lucha política y las contradicciones de clase parece venir de la incómoda vecindad de estos términos en un mismo marco conceptual, es decir, de su coexistencia en un tipo de lectura del presente que apuntara a una conceptualización simultánea de las escisiones internas existentes en formaciones sociales específicas, de las condiciones de la perdurabilidad de estas últimas en el tiempo, y de su transformación.

Tal es el caso de la conjunción teórica de los conceptos de reproducción, lucha política y contradicción de clase característica de los esfuerzos de conceptualización de las formaciones sociales capitalistas tardías como totalidades complejas sobredeterminadas que Louis Althusser elaboró fundamentalmente en las décadas de los años 60 y 70 del siglo pasado, y que analizaremos en el segundo apartado. Ese esfuerzo teórico no solo habilitaría hoy una lectura 
crítico-ideológica de ciertos impasses existentes en las aproximaciones contemporáneas al neoliberalismo sino que ayudaría a superar su fragmentación característica, tejiendo una trama común en la que confluyeran elementos destacados por esos diversos énfasis analíticos.

Esa confluencia no podría darse, sin embargo, al modo de una unificación de las perspectivas existentes. Desde la "perspectiva de la reproducción" se trataría más bien de conjunciones tensionadas y dispuestas a hacer crujir sus conceptos más propios en favor de una tematización de la complejidad; concretamente: en favor de una tematización del modo -sobredeterminado- en que en cada caso la explotación de clase es afectada en su centro por la reproducción de mecanismos de poder relativamente autónomos, y estos por prácticas de subjetivación política que, a su vez, solo abstractamente podrían ser consideradas como invenciones de la política, indiferentes tanto a la perpetuación de la explotación como de la dominación.

La hipótesis de lectura de la que aquí partimos sostiene que al margen de esa sobredeterminación resultan ininteligibles una serie de procesos que han venido teniendo lugar en las formaciones sociales capitalistas durante las últimas décadas tanto a nivel global como regional y particularmente en el caso de Argentina. Si la tesis de una esencia inherentemente autoritaria de la "razón neoliberal" no permite comprender las luchas por la democratización emergentes en muchos países de la región atravesados por procesos de neoliberalización, tanto en términos económicos como políticos, la comprensión de ese autoritarismo como un síntoma de la impotencia ideológica de las clases actualmente dominantes cede a un diagnóstico de primitivización de las condiciones de explotación, en el que la materialidad y especificidad de la ideología tienden a diluirse. ¿Permitiría acaso una teoría del neoliberalismo como racionalidad consumada $-\mathrm{y}$ no como una tendencia en conflicto 
activo con otras- explicar la emergencia de procesos políticos expresamente anti-neoliberales durante las últimas décadas en varios países latinoamericanos? ¿Sería posible asociar, en estas latitudes, las emergencias autoritarias a una literalización del capitalismo que habría sido ajena al tipo de organización societal impulsada por corrientes identificadas con el liberalismo? Si el neoliberalismo fuera expresión de un capitalismo decadente, ¿cómo es que persiste, reproduce y adquiere sentido desde el punto de vista de los individuos-sujetos que sostienen hoy -y están incluso dispuestos a militar- sus configuraciones más extremas? ¿Cómo se explicarían los intensos fenómenos de conflictividad política y movilización sindical que se viven en países como Argentina a la luz de diagnósticos generales de despolitización, apatía, desmovilización y sustitución de los sujetos colectivos por un individualismo pleno? A la inversa: ¿cómo explicar el fracaso de proyectos democratizadores a partir de una intelección abstractamente política de los mismos? Si el foco exclusivo del análisis recae en estas articulaciones políticas pos-neoliberales ¿no se pierde de vista el modo en que de hecho se ven afectadas por las condiciones de reproducción de la explotación capitalista? Las páginas que siguen procuran recuperar algunos elementos de la teoría althusseriana a fin de empezar a pensar lo que de otro modo se asemeja más bien a una serie de enigmas insondables.

\section{Tres aproximaciones críticas al neoliberalismo}

El primero de los enfoques cuyos señalamientos no deberían ser pasados por alto en una consideración teórica crítica del actual estado de neoliberalización de nuestras sociedades resulta muy claramente representado por Wolfang Streeck en ¿Cómo terminará el capitalismo? Ensayos sobre un sistema en decadencia (2017). A través de cierta actualización del andamiaje conceptual provisto por 
el materialismo histórico, el neoliberalismo resulta caracterizado a partir de un conjunto de políticas económicas desreguladoras distintivas, según Streeck, de una fase del capitalismo cuyas clases dominantes habrían perdido su vocación hegemónica y que potenciaría sus tendencias hacia la autodestrucción, desatando procesos altamente disolubles desde un punto de vista social y desdemocratizadores desde un punto de vista político (Streeck, 2017: 41). Como paradójico efecto de la liberación del capital a su propia lógica a partir de los ańos setenta, el capitalismo viviría hoy una "vida de ultratumba" (Streeck, 2017:15) traducida en la generalización de "un modo de vida infra-institucionalizado" (Streeck, 2017 :55) y un tipo de "sociedad infra-gobernada" (Streeck, 2017: 55).

Si bien este diagnóstico resulta fundamental para iluminar el papel que las políticas neoliberales desregulatorias jugaron en el relanzamiento del capitalismo durante el último tercio del siglo pasado -lo cual suele omitirse cuando se habla solo del primer término, sin referencia al segundo- y para ayudarnos a pensar sus paradójicas consecuencias, su definición del modo de producción padece de un cierto reductivismo económico en cuyo marco los mecanismos coercitivos e ideológicos -sintetizados por el autor como "palos y zanahorias" (Streeck, 2017: 16) - tienden a ser pensados de un modo simplificado e instrumental, como si constituyeran un mero ańadido a las políticas económicas y que, eventualmente, podrían llegar a suprimirse. Bajo estos supuestos, el análisis crítico tiende a reduplicar paradójicamente la imagen economicista y pos-ideológica que -sobre todo durante la década de 1990- las fuerzas políticas promotoras del neoliberalismo insistieron en proyectar respecto de sí mismas, pero además encuentra serios límites para explicar por qué y de qué modo las supuestas tendencias decadentes consiguen no obstante una alta eficacia ideológica y política. $\mathrm{Al}$ ser caracterizadas las formaciones sociales neoliberales como sociedades "infra-institucionalizadas", "infra- 
gobernadas" o anómicas se pierde de vista aquello que -dicho en una terminología cara al posestructuralismo más vigente- el neoliberalismo produce: valores, relaciones subjetivas afectivas con los mismos y formas de socialización propiamente neoliberales, sobre las cuales pondrá el foco del análisis su interpretación como un tipo de "racionalidad" específica.

$\mathrm{Al}$ partir del concepto acuñado por Foucault como parte de su cuestionamiento al concepto de ideología (2000), Wendy Brown (2005 y 2015) focaliza precisamente en esos mecanismos productivos y piensa al neoliberalismo como una racionalidad por la cual se generaliza el principio de la competencia y se introduce un novedoso régimen de subjetivación -ligado a la expectativa de que toda acción pueda ser sometida a una consideración en términos de beneficio y siguiendo un cálculo de utilidad- que mina seriamente la posibilidad de constitución de una subjetividad autónoma. Antes que simplemente sobrevivir en una situación de anomia y/o amoralidad generalizadas, la vigencia y reproducción de la dominación vendría ligada en la actualidad a un sumamente activo, potente y paradójico trabajo de moralización totalitaria de la vida social que sería propio de la racionalidad neoliberal y que habría arrasado con el mismísimo sujeto autónomo en su capacidad para concebir y cuestionar la "necesidad" socialmente impuesta. Si bajo la idea de poshegemonía el capitalismo contemporáneo parece impotente para codificar, la noción de "racionalidad neoliberal" sugiere la contrafigura especular de un universo donde todo ya ha sido codificado en un mismo sentido por una razón sin lado de afuera ni contradicciones y que solo resta describir en su objetividad omnipotente. Esa unilateralidad termina convirtiendo a una aproximación relevante para dimensionar ciertas determinaciones estructurales que operan sobre el presente en una perspectiva que de algún modo duplica las tendencias paranoicas y a la vez reconciliadas predominantes en él, diluyendo la cuestión de la reproduc- 
ción de las condiciones de producción capitalistas en una crítica de la dominación o de "el poder" en general, y dejando además intacta la auto-representación del neoliberalismo como una fuerza ilimitada. Brown deja, en efecto, sin tematizar el modo concreto en que "esas transformaciones normativas del neoliberalismo son determinadas por las historias políticas nacionales, se superponen con otros regímenes de subjetivación políticos y se articulan o transforman determinados núcleos de sentido de las democracias realmente existentes" (Wegelin, 2017: 14). Y es esa ausencia la que, como ha señalado Etienne Balibar (2013), hace que en su análisis de las potencias normativas del neoliberalismo estas aparezcan absolutizadas: frente a ellas no hay nada y las huellas que los conflictos políticos dejan en las instituciones vigentes se vuelven ilegibles pese a todo para su crítica de la razón neoliberal.

Contra las tentaciones de diagnósticos que, ya sea mediante el despliegue de la lógica del capital o a través del concepto de racionalidad neoliberal, resultan en una concepción totalizante del poder, parece conveniente retomar otras perspectivas críticas que, paradas en el campo del postmarxismo y en diálogo con algunos elementos de la teoría del discurso foucaultiana, han puesto el foco en la lógica antagónica de la política, con el objetivo de volver pensables los procesos y dinámicas propias de la configuración de fuerzas políticas, aglutinamientos y antagonizaciones que permiten abordar la escena contemporánea en clave de las tensiones y contradicciones que hacen a la condición controversial de cada coyuntura. En este sentido, el aporte realizado por la teoría política de Ernesto Laclau y Chantal Mouffe (2005a) entre otros desarrollos atentos a la inherencia conflictual de toda unidad social, ofrecen algunos elementos para pensar críticamente el neoliberalismo. Esta perspectiva compartiría con la anterior el énfasis político, pero en lugar de una racionalidad inexorable e inherentemente antidemocrática, afirmaría la condición precaria y antagónica del 
neoliberalismo, entendido como articulado plural, contingente e inestable de alianzas particulares, forjadas en procesos litigiosos de subjetivación política.

El intento de emancipación del pensamiento de "la política" de su subordinación a lo social por parte del marxismo, y la comprensión de esa politicidad en términos de una operatoria formal de articulaciones discursivas, que Laclau ensayó a partir de los ańos ochenta, tienden a diluir la complejidad de las determinaciones históricas operantes en las formas concretas de subjetivación y articulaciones políticas posibles. El desajuste clásico entre la estructura económica (modo de producción) y la formación social concreta en la que esta existe históricamente como su causa ausente -que Laclau había trabajado en los setenta (1978) - es reformulado en los términos del desajuste entre una formación discursiva y el campo de la objetividad discursiva. A partir de considerar al discurso como el "terreno primario de constitución de la objetividad como tal" (2005: 92), la pregunta por la política como problema de la conflictividad constitutiva de toda formación social y de la lucha de clases, es reemplazada por una concepción de la política como lógica diferencial/equivalencial de composición identitarias, cuyos límites radican menos en la índole discursivista del planteo que en su consideración restringida de los vínculos entre discurso e historia. Divorciada del complejo ensamble de relaciones que la constituyen desde su exterior, una formación discursiva asume la forma de una interioridad fenomenológica, ofreciendo una versión depurada y formalista de las luchas históricas, abstraídas de la complejidad histórica de las configuraciones y procesos de significación que restringen y determinan en las escenas concretas el juego contingente.

Los análisis de los procesos sociales y políticos contemporáneos parecen encontrarse, de este modo, en una situación de enclaustramiento e incomunicación paralizante. De un lado enfoques de 
raigambre marxista que, si bien empiezan por definir a lo neoliberal como un relanzamiento del capitalismo en los 80 , en realidad tienden a reducirlo a la aplicación de un conjunto de medidas económicas y arrojan un diagnóstico de desnudamiento de la dominación, anomia o regresión en el que prima todo lo que el neoliberalismo destruye y que, consiguientemente, no pueden más que asombrarse al comprobar que a pesar de todo dure. De otro lado, enfoques que resaltan la productividad del neoliberalismo como una racionalidad política pero que paradójicamente lo idealizan como una forma de dominación omnipotente situada más allá de todo conflicto político. Mientras los primeros se hacen la pregunta por las condiciones sociales y los efectos del capitalismo neoliberal pero no pueden pensar su productividad ideológica, las críticas a la "dominación" neoliberal dan cuenta de su posibilidad de perpetuación a través de la producción de identidades normativas, pero sus preguntas por "el poder y sus formas de ejercicio" no solo disocian esa productividad de la reproducción social bajo el dominio de una clase, sino que tampoco interrogan las correlaciones de fuerzas políticas en sociedades concretas. Estas últimas parecían constituir, por el contrario, el objeto de análisis propio de las perspectivas hegemonistas que, no obstante, tal como hemos visto a propósito de Laclau, suelen reducir a la política a un plano discursivo en el que el proceso histórico tiende a volatilizarse debido entre otras cosas a la ausencia de una conceptualización positiva de las múltiples determinaciones concretas y desniveladas que definen a una coyuntura singular. En este sentido, una perspectiva del neoliberalismo como hegemonía incurre en un reduccionismo político que solo encuentra lo que de antemano va a buscar. Si a diferencia de la perspectiva encarnada por Wendy Brown, se trata de un politicismo que ontologiza el "conflicto" y pone el énfasis en la precariedad del orden, al igual que en la perspectiva de la racionalidad se produce aquí, finalmente, una exacerbación del proble- 
ma de la "dominación", disociado del problema de la reproducción material de la sociedad.

Como veremos en el próximo apartado, el doble desviacionismo que podría constatarse en las perspectivas hasta aquí reseñadas, se aproxima a las posiciones economicistas y politicistas que Althusser criticaba en la década de 1970; al punto de que podríamos incluso sostener que su existencia disociada constituye un síntoma de la ausencia de una teoría compleja de la sociedad como la que él aspiraba a producir. Apoyándonos en esta conjetura podemos acercarnos a la teoría althusseriana de la reproducción social, a fin de buscar en ella algunos elementos que nos permitan superar el impasse en el que se encuentran los abordajes actuales sobre el neoliberalismo. En contraste con el politicismo, la clave de la teoría althusseriana de la reproducción social radica en su esfuerzo de integración del análisis de la dominación política en una teoría de las formaciones sociales capitalistas que produce a la vez conceptos para el análisis ideológico de las formas específicas en que se perpetúa conflictivamente la dominación en el capitalismo contemporáneo a pesar de los efectos materialmente desintegradores que tiene la implementación de las políticas económicas neoliberales. Debido a esto último, su abordaje permite también sortear las tendencias economicistas de las teorías marxistas del neoliberalismo que, aún cuando lo caractericen como una dominación de clase, privan a aquello que consignan como ideología de un desarrollo histórico propio, asumen su reductibilidad a otros procesos sociales y, por ello mismo, necesariamente subestiman su eficacia y productividad específicas.

\section{Sobre la Reproducción}

A la luz de las aproximaciones al neoliberalismo que hemos reseñado, la perspectiva althusseriana presenta, en efecto, un doble des- 
ajuste, de objeto y de método: repone una pregunta por lo histórico-social que plantea la necesidad de una elaboración teórica de conjunto formulada en el campo conceptual marxista, y concibe a esa teorización como una intervención crítico-ideológica en una coyuntura precisa que trabaja sobre y se reconoce afectada por las representaciones dominantes en ella.

Sin ser nueva, la urgencia de una conceptualización justa de la totalidad social es formulada con todas las letras en un texto póstumo de Althusser del cual hasta hace relativamente poco solo conocíamos un extracto publicado en La Pensée bajo el título de "Idéologie et appareills ideologiques d'État": Sur la reproduction (2011). En este volumen, escrito entre 1969 y 1970, Althusser sostiene que para poder pensar cómo es que se reproducen/transforman las relaciones de producción/dominación, estamos obligados a replantear una vieja cuestión: ¿qué es una sociedad? Considerada tanto sobre el fondo de los análisis de las transformaciones económicas operadas en un capitalismo pos-keynesiano y presuntamente "pos-político", como así también respecto de las descripciones de la politicidad neoliberal que hemos revisado, esta resulta sin duda una preocupación extrańa e incluso anacrónica, con su aspiración a la totalidad y a la "comprensión de conjunto" de lo social. Pero semejante "desfase" en relación a lo más contemporáneo podría constituir un signo de su potencia cognitiva en un doble sentido. Por una parte, como generadora de una conceptualidad capaz de superar las tendencias a la fragmentación del análisis -que tienen como su contracara la absolutización de las dimensiones consideradas- gracias a la tematización de la existencia articulada y de la incidencia diferencial de las diversas prácticas en una formación social concreta; por otra parte, en tanto crítica o, más precisamente, "lectura sintomática" de nuestro presente teórico, permitiría poner en relación las obsesiones y los olvidos de una contemporaneidad que o bien tiende a pensar la política como ya perdida 
para un presente "pos-hegemónico", o bien quiere pensarla "directamente" y "en sus propios términos" como si la "racionalidad" o la "hegemonía" de lo neoliberal fueran independientes de o ajenas a la reproducción de las condiciones de explotación en el capitalismo. Frente a ambas, la pregunta althusseriana por la sociedad habilita una reflexión dialéctica sobre la "autonomía relativa de las superestructuras" por la cual la política aparece a la vez como una dimensión singular e irreductible de las formaciones sociales que tiene su propia historia y conflictividad interna, $y$ como falsa en su pretensión de independencia. Dicho en otros términos, la pregunta por la sociedad dispara en Althusser un pensamiento de la reproducción/transformación de lo socialmente dominante solidario del concepto de totalidad sobredeterminada, en el cual la "autonomía de lo político" asume una doble valencia crítico-ideológica, como ilusión proyectada por la ideología jurídico-política burguesa, $y$ como aquello que el materialismo vulgar desconoce; como lo invisibilizado $y$ lo fetichizado a la vez.

Esta conceptualización resulta sumamente relevante para nuestro abordaje actual de lo neoliberal porque si en oposición a un diagnóstico de la dominación desnuda nos recuerda que no hay "sobrevida" posible del modo de producción capitalista al margen de un intenso trabajo (superestructural) de reproducción de las condiciones de la producción, demarcándose de un pensamiento de lo específicamente político nos plantea simultáneamente la necesidad de tematizar la productividad política en su forzada coexistencia con la reproducción social. Pero la "perspectiva de la reproducción", al margen de la cual, dice Althusser, todos los hechos aparecen necesariamente deformados (Althusser, 2011: 82) no se presenta a sí misma como un principio teórico alternativo, impoluto y ajeno al error que permitiría ver las cosas en su verdad como si se sencillamente se tratara de abrir los ojos por primera vez. Antes que una posición primera, radicalmente autónoma de la 
mirada, el "punto de vista" de la reproducción es, simultáneamente, repetición de una vieja (“¿qué es una sociedad?”), producción de una conceptualidad faltante, y crítica de lo falso, esto es, respuesta a determinadas representaciones de la sociedad constituidas en función de las "evidencias" en las que se perpetúan formas de desconocimiento de la estructura social asociadas a las necesidades de reproducción de las relaciones de producción basadas en la explotación.

En el texto Sur la reproduction, Althusser refiere extensamente su propio movimiento de conceptualización de lo social a dos conjuntos de representaciones ideológicas vigentes. Por una parte, el "economicismo" despolitizador y tecnocrático que pretende encontrar el fundamento de la organización social existente en las necesidades técnicas de la producción o en el desarrollo de las fuerzas productivas aisladas de las relaciones bajo las cuales ese desarrollo tiene lugar. Por otra parte, el "hiperpoliticismo" que, en Mayo del 68, se plasma en un discurso anarquizante de la rebelión y la revuelta contra el poder en general (Althusser, 2011: 210) que desvincula la transformación política de las luchas contra la explotación económica. Ya sea que el énfasis se coloque en la lógica de la dominación o en el desarrollo de la técnica, en la política o en la economía, el problema es que la complejidad social resulta reductible en estas perspectivas a un hecho social básico que permitiría explicar a partir de sí mismo la complejidad efectiva como un mero derivado de su propio desarrollo, en un movimiento de abstracción que tiene como efecto un concepto expresivo de totalidad al que ya en La revolución teórica de Marx Althusser había criticado a propósito de la conciencia hegeliana: "Círculo de círculos, ella no tiene (para Hegel) sino un centro, que es el único que la determina: necesitaría poseer círculos que tuvieran otro centro que el de ella, círculos descentrados para que pudiera ser afectada en su 
centro por su eficacia, para que su esencia fuera sobredeterminada por ellos. Pero este no es el caso" (Althusser, 1999: 82).

Es esa lógica expresiva la que Althusser lee en ciertas consignas del Mayo del 68 donde la represión deviene "el centro de centros, la esencia de la sociedad de explotación de clase capitalista" donde la ideología e incluso el Estado "resulta reductible a la noción abstracta de la represión" (2011: 211). Y a ella responde elaborando teóricamente el concepto de Aparatos Ideológicos del Estado (AIE) que son simultáneamente 1) instancias donde se garantiza la reproducción de las condiciones de la explotación; 2) diversos de los Aparatos Represivos del Estado (ARE) en tanto producen efectos de subjetivación y el conjunto de evidencias en que se desarrollan las prácticas cotidianas sin apelar directamente a la violencia física sino más bien a rituales de reconocimiento; 3) instancias de reproducción/transformación de la ideología dominante en tanto cristalizaciones de la lucha de clases, y 4) uno de los lugares privilegiados donde esa lucha se desarrolla.

Contra las evidencias de la represión, el concepto de AIE busca reponer la complejidad de los mecanismos de la dominación en el doble sentido de su diversidad irreductible (ARE/AIE, ambos en plural) y también de las incoherencias y desajustes internos existentes entre los aparatos ideológicos, cuyas junturas "rechinan" (Althusser, 2011: 170 y 233). Paralelamente, donde el tecnocratismo/economicismo ve una lógica de la producción, primera y desnuda, que solo con posterioridad se complejizaría en superestructuras simbólicas, sistemas jurídicos y conflictos políticos que eventualmente "reaccionan" sobre la base, Althusser lee otra suerte de mito de los orígenes absolutos que se constituye al disociar ilegítimamente la existencia de una formación social de su duración en el tiempo (Althusser, 2011: 196). A pesar de lo que sugiere esta lógica lineal del antes y el después, "la reproducción no es más que la condición de la existencia continuada de la producción" 
(Althusser, 2011: 160), y la "reacción" de la superestructura "no es en absoluto una reacción puesto que la superestructura mantiene con la base la relación específica de reproducir las condiciones de funcionamiento de la infraestructura” (Althusser, 2011:195).

A partir de estos señalamientos la "perspectiva de la reproducción" queda determinada en tres aspectos claves para nuestra lectura. En primer término, la perspectiva de la reproducción es crítica de la ideología. De la conceptualización de la existencia material y la eficacia histórica de la dimensión ideológica en su irreductibilidad a otras (económicas, políticas, cognitivas, estéticas, etc.) se sigue la exigencia para la perspectiva crítica materialista de una ruptura con las formas ideológicas dominantes que, en una coyuntura específica, asedian al pensamiento teórico y tienden al empobrecimiento del diagnóstico subsumiéndolo a representaciones que operan un necesario opacamiento de la complejidad histórica y contradictoria del todo social.

En segundo término, la perspectiva de la reproducción es un pensamiento de la sobredeterminación y un conocimiento de la totalidad compleja. El concepto de reproducción no se emplaza en los términos de una oposición entre economía y política con el fin de establecer una sustancia última de la sociedad, sino contra cierta forma de concebir lo económico y lo político como "centro de centros" de lo social, y como instancias internamente puras, no contaminadas o "afectadas" en su esencia por los otros de sí mismas con los cuales se encuentran enlazados en la especificidad de una cierta relación. Si en el primer aspecto la perspectiva de la reproducción se muestra ante todo como respuesta críticoideológica, en este segundo aspecto lo hace como perspectiva de la sobredeterminación, según la cual nunca accedemos a ningún elemento simple y primero.

En tercer lugar y en relación con lo anterior, el "punto de vista de la reproducción es el punto de vista de la lucha de clases" 
(Althusser, 2011: 251) en términos marxistas, es decir, apunta a una comprensión de la conflictividad social como irreductible "a una suma de enfrentamientos puntuales o limitados a tal o tal otra 'esfera' (economía, política, ideología)" y evita asimismo una ontologización del conflicto "en general", orientándose en cambio a una conceptualización de las luchas sociales efectivas como parte de un proceso de conjunto en cuyo marco los conflictos revelan una capacidad de incidencia desigual (Althusser, 2011: 184). No obstante, el planteo althusseriano introduce a su vez transformaciones relevantes en muchos de los conceptos claves de la tradición marxista y en el modo de pensar su articulación.

Una de esas transformaciones se asocia a la nueva centralidad del concepto de formación social capitalista, a cuya luz el "modo de producción" se devela como incapaz de explicar por sí mismo la complejidad de los conflictos de una formación social, en la cual existe siempre más de un modo de producción. Aún asumida en su estricta lógica económica, toda formación social se encuentra tramada por contradicciones inherentes a un modo de producción pero también por contradicciones propias de la articulación jerárquica entre modos de producción heterogéneos.

Otra de esas transformaciones, referida a la introducción del concepto de sobredeterminación, apunta a la idea de explotación capitalista que, según Althusser, tampoco puede ser asumida como un punto de llegada de la ciencia marxista de la sociedad como si se tratara de un dato básico o de un principio absoluto. La explotación nunca se da "desnuda", "antes" de unas relaciones de producción que, bajo la forma de títulos jurídicos, intervendrían solamente más tarde "para justificar y sancionar jurídicamente la detención de medios de producción y productos" (Althusser, 2011: 80). Contra esta imagen de una explotación anterior y desnuda que postula a las mediaciones como redundantes, posteriores, yen consecuencia- básicamente eliminables, la perspectiva de la re- 
producción muestra de qué manera aquella, para llegar a ser lo que es, siempre tiene que pasar por algo que no es directamente explotación. Por caso, en las sociedades capitalistas avanzadas, tiene que pasar por el derecho, el Estado y las declaraciones de la igualdad que, a su vez, en el argumento de Althusser son ilusorias y simultáneamente no lo son. Si el prejuicio de la igualdad vehiculiza la desigualdad estructural, a la inversa, la desigualdad -efectiva- está investida de la imaginación de la igualdad: habla "en nombre de" una igualdad que, en su lucha, las "masas populares" deben "tomar al pie de la letra" (prendreaumot), tomándole la palabra a la democracia burguesa allí donde la revuelta querría -en cambio- omitir ese segundo nivel y quedarse con la inmediatez de una homogénea dominación (Althusser, 2011: 147).

En tanto perspectiva de la lucha de clases, la perspectiva de la reproducción concibe a los aparatos de Estado burgueses como encargados de garantizar las condiciones de reproducción de la explotación capitalista no solo mediante la represión sino fundamentalmente mediante la constitución de los sujetos requeridos a tal efecto. Pero bajo esa misma perspectiva, la reproducción se revela como objeto de un incesante litigio y la solidez de la dominación como una "armonía rechinante" (Althusser, 2011: 174). Siendo los aparatos de Estado (particularmente en el nivel ideológico) a la vez escenarios y efectos de esa lucha, ellos permiten comprender al Estado más allá de la definición "idealista-instrumentalistaburguesa" que lo presenta como un "puro instrumento de la dominación y de la represión al servicio de los objetivos, es decir, de la voluntad consciente de la clase dominante" y cuya contraparte es una "concepción idealista (humanista) burguesa de las clases sociales como 'sujetos'” (Althusser, 2011: 108).

De esta triple modulación de la "perspectiva de la reproducción" como perspectiva de la lucha de clases, pensamiento de la sobredeterminación, y crítica de la ideología, pueden derivarse al- 
gunos requerimientos althusserianos para una lectura del momento actual.

1) La intelección del complejo de relaciones y procesos de la formación social capitalista en su coyuntura neoliberal no podría seguirse del desarrollo de las tendencias inmanentes a la lógica económica del capital, ni de la descripción de una doctrina exitosa o una "lógica" de gobierno de las conductas, sino que requiere una elaboración atenta a las modulaciones específicas de lucha de clases en una formación social que, en sus formas concretas, solo existe sobredeterminada por una multiplicidad de contradicciones de índole ideológica, política, etc.

2) Esa elaboración exige el sostenimiento de la pregunta por la totalidad social en su consistencia compleja y contradictoria. Incluso allí donde no es posible localizar contendientes políticos fuertes e identificables o contradicciones ideológicas. Esto se debe al efecto general de conjunto de un complejo de contradicciones, a cuya forma específica asisten singularidades económicas, ideológicas y políticas, ellas mismas contradictorias, por más totalizante que se muestre su eficacia. Por otra parte, una crítica del neoliberalismo en términos de racionalidad que le prestara una suerte de consistencia espiritual a la "lógica de la dominación" y enfatizara unilateralmente la incidencia efectiva de los procesos de unificación imaginaria de la experiencia social conforme a las necesidades de la reproducción social, necesariamente perdería de vista su desajuste constitutivo y la objetividad contradictoria (Balibar, 1993) y no clausurada de las formaciones históricas, así como los desajustes propios de la inscripción de los individuos en los dispositivos de subjetivación, cuyas lógicas de interpelación, por apoyarse en la economía inconsciente, fallan estructural e irremediablemente.

3) Es preciso, entonces, perseverar en el concepto de ideología, que es el único capaz de tematizar la articulación compleja entre realidades psíquicas y dispositivos histórico-sociales de acomoda- 
ción a la reproducción social asumiendo su doble desajuste: el que resulta del resto inconsciente de todo proceso de identificación subjetiva, y aquel derivado de las tendencias contradictorias que se libran en el espacio material de los dispositivos de subjetivación. Esas contradicciones nos obligan, a su vez, a reconocer las potencias diferenciales de lo imaginario para la práctica política: no solo su irreductibilidad, sino su eficacia específica y situada en relación con la coyuntura en la que las formaciones imaginarias se sobredeterminan con un complejo heterogéneo de discursos y prácticas (Romé, 2019).

4) En cuarto lugar, la perspectiva althusseriana reclama que la crítica se desarrolle como análisis de una coyuntura específica, en la que quede expuesta la precariedad de un poder sometido a procesos políticos conflictivos, pero evitando simultáneamente una reducción coyunturalista, que aplane la trama compleja de temporalidades heterogéneas que prestan al caso su densidad y concreción históricas. Si bien las perspectivas que ponen el foco en el conflicto asumen esa inestabilidad constitutiva de la duración, no logran conectar las dinámicas políticas con las determinaciones que confluyen en su coyuntura, ontologizando su condición contingente. Esto tiene consecuencias fuertes con respecto a la ponderación de las fuerzas en pugna, el alcance o limitación de su potencia y las jerarquías y desigualdades que determinan la "contingencia" de sus articulaciones y prohíben la disolución de los tiempos largos de las regularidades tendenciales en los tiempos cortos de las maniobras estratégicas y tácticas.

Para concluir. El caso argentino: neoliberalización y crisis del humanismo en la periferia del capitalismo tardío

Un abordaje que tome rigurosamente en cuenta, en su consistencia histórica y sobredeterminada, el problema de la reproducción social, debe 
sospechar de toda consideración de un Neoliberalismo "en general" y localizar, en cambio, los niveles y alcances de su condición coyuntural como parte de la transformación procesual del equilibrio que permitió la duración y reproducción ampliada del capitalismo, en el marco de la larga y agónica crisis de su momento imperialista. Este tránsito hacia un grado mayor de concreción permite conectar los procesos "globales" con una posición determinada en la división internacional del trabajo y una específica constelación de relaciones políticas y formaciones ideológicas que esta trae consigo pero que resultan a su vez tensionadas en el derrotero histórico de sus contradicciones nacionales y regionales específicas, así como el de las luchas concretas que tienen allí su lugar.

Emplazada en este marco, la coyuntura política argentina más inmediata, representada por la experiencia macrista, puede ser problematizada en su apariencia de un puro efecto de ingenierías políticas acertadas, sin tener que ser por ello comprendida como mera "expresión" de un momento punitivista o especialmente autoritario del Capital global. La restitución de la complejidad de determinaciones que en ella se condensan, permite leer los procesos largos en los que se cimienta la eficacia ideológica, es decir afectiva e inconsciente, de los discursos y prácticas impulsados por esa fuerza política, a la vez que las singulares contradicciones que la causan: no solamente las más abstractas "de clase", ni las más "políticas" entre soberanías estatales y tendencias globales, sino las propias de la desigualdad centro-periferia.

$\mathrm{Al}$ partir de un consenso amplio -aunque disímil en sus periodizaciones largas (Brown, 2018; Murillo, 2008) o cortas (Davies, 2016; Berardi, 2017) - respecto a la actual coyuntura neoliberal global como una coyuntura tendencialmente des-democratizadora y autoritaria, es preciso interrogar las determinaciones específicas de esa condición: sus contradicciones concretas y las luchas políticas singulares que tensionan de modo inmanente la textura dominante de sus formaciones ideológicas, a la vez que explican 
su tendencial eficacia. Así, los rasgos identificables en la reciente coyuntura argentina que pueden sintetizarse como marcas de una transformación ideológica inmanente al proceso de neoliberalización desde una discursividad tecnocrática, desapasionada, consumista y globalizante -en los ańos noventa- hacia interpelaciones basadas en la domesticidad del núcleo íntimo, la imaginación punitiva y la llamada culpabilizadora al ajuste sacrificial como expiación de un pasado de excesos populistas (Catanzaro/Stegmayer, 2019), convocan un complejo de genealogías contradictorias sin las cuales su sola descripción se vuelve abstracta.

El neoliberalismo argentino tiene un momento acontecimental con la última dictadura militar iniciada en 1976 en la que confluyen las medidas de liberalización financiera, reprimarización económica y libre mercado, con el recrudecimiento de las funciones represivas del Estado y su retiro de las políticas regulatorias y de cuidado. Esa "presentación en sociedad" tuvo muchos de los rasgos segregacionistas, xenófobos, racistas, hiperpatriarcales y reaccionarios que, abstraídos de la complejidad material de las relaciones sociales, hoy son considerados inéditos y sorprenden a muchos analistas. Tramada tempranamente con los procesos de expansión extractiva del capital financiero y la irracionalidad del endeudamiento, esa lógica autoritaria concitó también disposiciones afectivas basadas en el terror y la culpabilización. Así, ella encuentra más regularidades que "novedad" en la larga historia imperialista, e incluso hunde sus raíces en las relaciones coloniales. Pero del mismo modo que esta tesis no basta para dar cuenta de sus modulaciones específicamente neoliberales, el carácter “jurídico-político" de los comienzos del proceso de neoliberalización en las experiencias dictatoriales de Sudamérica resulta anecdótico si no se restituye la densidad de sus vínculos con las contradicciones propias de las relaciones centro-periferia y las luchas políticas asociadas a ellas: los movimientos tercermundistas, los procesos de radicalización de 
masas y las luchas de liberación nacional, que tuvieron lugar entre fines de los años cincuenta y comienzos de los ochenta. Es como respuesta reaccionaria a esa contratendencia abierta en el marco de la crisis de acumulación imperialista que se entienden las formas específicas de violencia dictatorial del primer neoliberalismo, sus aspectos internacionales y sus dinámicas sistemáticas y masivas de disciplinamiento social.

Tales contradicciones y antagonismos políticos específicos permiten entender la contingencia sobredeterminada del capitalismo neoliberal autoritario periférico en su comienzo, pero también las dinámicas contradictorias de su duración, convocando otras genealogías que ritman los diversos momentos del proceso de transformación neoliberal con las renovadas formas de lucha y resistencia antiimperialista que volvieron a manifestarse en los años noventa, con la experiencia zapatista y el llamado "Caracazo" y, a principios del nuevo siglo, con la llamada "Guerra del agua” en Bolivia y el estallido popular argentino en diciembre del 2001. Estos episodios marcan la singularidad del neoliberalismo latinoamericano, heterogéneo y desajustado, y de subjetivaciones políticas que traman lo nuevo y lo arcaico en específicas formas estratégicas y tácticas de lucha, como las del mas en Bolivia, el kirchnerismo en Argentina, el antiimperialismo militar en Venezuela, etc. No se trata de meros "intersticios" o "reacciones combativas" de orden secundario, ni de puros efectos de articulaciones tan contingentes como demiúrgicas, sino más bien de procesos de subjetivación sobredeterminada de las tendencias contradictorias de la reproducción social en coyunturas específicas.

Ese mismo carácter concreto impone límites históricos a sus potencias articulatorias: los límites propios de un campo de lucha marcado por la dominancia ideológica neoliberal. Más justo que caracterizar como "post-neoliberales" a los procesos progresistas recientes (Sader, 2008) resulta pensarlos como procesos de subjeti- 
vación contra-tendenciales, que no necesariamente constituyen ni una "etapa otra" que la neoliberal, ni una "identidad política antineoliberal". En su tendencia unificadora la ideología dominante es también efecto de esas luchas, y simultáneamente afirma su eficacia en su capacidad para desconocerlas. Las contra-tendencias son todavía abstractas si no se piensan sus tensiones con las tendencias ideológicas dominantes que, al marcar sus límites y posibilidades, trabajan coadyuvando a la duración del proceso de neoliberalización a pesar de los antagonismos que lo obstaculizan.

Ahora bien, por un lado y paradójicamente, la dimensión pertinente para el análisis de la coyuntura neoliberal en sus aspectos ideológicos exige situarse en una genealogía aún más larga, que podríamos caracterizar como la crisis de la formación ideológica humanista, que se extiende a los albores de la consolidación del sistema-mundo capitalista. Esa crisis opera en el nivel de lo que podríamos considerar el régimen de historicidad que marca la experiencia contemporánea del tiempo histórico como una absolutización del presente y como una mutación de la metáfora de la línea a la del círculo, que ha sido caracterizada como experiencia presentista (Traverso, 2018; Ré, 2020), pos-utópica (Catanzaro2019) y totalitaria (Romé, 2016, 2020). Esa crisis del humanismo, que en parte dejó expuesto el costado mítico de un "progreso" y una "reconciliación” enhebrados con la perpetuación del dominio, las asimetrías sociales y la explotación de la naturaleza externa e interna, es también la crisis del proceso contradictorio de subjetivación popular-democrática en el espacio público contra la aristocracia y la superstición. En este marco puede entenderse la tendencial zozobra de la "ideología jurídica" que permite a los aparatos jurídicos formales funcionar con la idea de que todos somos libres e iguales “por naturaleza” (Althusser, 2011: 103-104). La decadencia de esa ideología jurídica occidental en sus componentes de imaginación igualitaria, deja intacto no obstante el complemento moral del de- 
ber, la obligación y la necesidad del castigo que se revitaliza en la ideología emprendedora y de meritocracia dominante naturalizando la competencia y la diferenciación social como principios vitales de lo humano. Y es esta naturalización de la desigualdad que produce subjetivaciones sacrificiales con deberes pero sin derechos, la que permite comprender el papel estratégico y las tremendas resistencias que las luchas por los derechos adquieren -como contratendencia- en las sociedades latinoamericanas contemporáneas. Los procesos democratizadores latinoamericanos de este último siglo revisten un doble "peligro": como contratiempo de las tendencias des-democratizadoras iniciadas en los setenta y como contratendencia ideológica en el marco de la crisis del humanismo.

En efecto, en la historia reciente argentina, la experiencia postapocalíptica y presentista del tiempo histórico lleva, además, las marcas de la post-dictadura que da tonos a la vida común con un empobrecimiento de la imaginación y un debilitamiento de las memorias de las izquierdas de masas y la cultura revolucionaria de los sesenta y setenta (Schwarzbock, 2015). En este sentido, el fenómeno político-ideológico neoconservador representado por el macrismo debe leerse también como reacción al contra-tiempo abierto por los gobiernos progresistas de principios del siglo XXI, para reinscribir esa sensibilidad postdictatorial de la destrucción normalizada, sumisa y autoritaria a la vez, con renovada violencia. De allí los rasgos anti-soberanistas que caracterizaron a la narrativa macrista extendida desde 2015 diferenciándola de los nacionalismos supremacistas europeos y estadounidenses. Su retracción hacia la interioridad y la domesticidad, es decir, hacia formas supuestamente pre o pos-políticas de pertenencia, retoma las tramas discursivas neocoloniales producidas por el plan sistemático de transformación de la matriz cultural implementado durante la última dictadura militar, con su restauración moral familiarista y su recuperación de la prosa simultáneamente xenófoba y subordinada 
a los poderes centrales característica de la "generación del 80", en la paradoja ideológica de un proyecto "modernizador-reaccionario" que conecta culpabilización y endeudamiento.

Disociado de la crisis del humanismo que en el plano ideológico permea la inflexión neoliberal del capitalismo a nivel global, el autoritarismo más o menos explícito de la experiencia macrista asume la apariencia de una aberración puramente local o periférica en la que vuelve a confirmarse la presunta excepcionalidad del totalitarismo para el capitalismo "normal". Paralelamente, disociado de la genealogía dictatorial y la historia colonial en la que se engaza ese autoritarismo, queda invisibilizada la fibra estructuralmente violenta y antidemocrática que marca la existencia concreta del capitalismo en nuestros países e invisibilizadas las luchas políticas suscitadas en su contra. La lectura de esa experiencia autoritaria como una coyuntura sobredeterminada destotaliza ambos gestos, persistiendo en la pregunta por la complejidad del caso, saturado de tensiones y tramado en temporalidades heterogéneas que fuerzan a pesar de todo su apertura hacia el porvenir.

\section{Bibliografía}

Althusser, Louis, 1999, La revolución teórica de Marx, Marta Harnecker (trad. e intro.), Siglo xxI, México.

, 2011, Sur la Reproduction, Etienne Balibar (prefacio), Jacques Bide (intro.), Prensas Universitarias de Francia, París.

, 2019, Escritos sobre la historia. 1963-1986, Carolina Collazo, Pedro Karczmarczyk y Marcelo Starcenbaum (trad.), PolvoraDoble Ciencia, Santiago de Chile.

Balibar, Etiènne, 2013, Ciudadanía, Rodrigo Molina-Zavalía y Adriana Hidalgo (trad.), Buenos Aires. 
Brown, Wendy, 2005, "Neoliberalism and the End of Liberal Democracy", en Edgework. Critical Essays on Knowledge and Politics, Princeton University Press, Princeton/Oxford, pp. 37-59.

, 2015, Undoing the Demos. Neoliberalism's Stealth Revolution, Zone Books, Nueva York.

, 2018, "Neoliberalism's Frankenstein: Authoritarian Freedom in Twenty-First Century Democracies", Critical Times, núm. 1, enero, pp. 60-79.

Catanzaro, Gisela y Stegmayer, María, 2019, "The New Neoliberal Turn in Argentina: Omnipotence, the Sacrificial Mandate, and the Craving for Punishment", Pedro Rolón Machado (trad.), Critical Times, núm. 2, abril, pp. 133-158.

Davies, William, 2016, "El nuevo neoliberalismo", New Left Review en español, núm. 101, septiembre-octubre, pp. 129-143.

Foucault, Michel, 2000, Defender la sociedad, Horacio Pons (trad.), Fondo de cultura Económica, Buenos Aires.

Laclau, Ernesto, 1978, Política e ideología en la teoría marxista. Capitalismo, fascismo, populismo, Siglo xxI, Buenos Aires.

, 2005, La razón populista, Fondo de Cultura Económica, Buenos Aires / México.

Laclau, Ernesto y Mouffe, Chantal, 2004, Hegemonía y estrategia socialista. Hacia una radicalización de la democracia, Ernesto Laclau (versión de), Fondo de Cultura Económica, Buenos Aires / México.

Murillo, Susana, 2008, Colonizar el dolor. La interpelación ideológica del Banco Mundial en América Latina. El caso argentino desde Blumberg a Cromañón / Susana Murillo, CLACso Ediciones, Buenos Aires.

Pêcheux, Michel, 2016, Las verdades evidentes. Lingüistica, semántica, filosofia, Mara Glozman, Pedro Karczmarczyk, Guadalupe 
Marando y Margarita Martínez (trad.), ccc Ediciones, Buenos Aires.

Romé, Natalia, 2016, "El presente totalitario de la ideología neoliberal”, Utopía y Praxis Latinoamericana, ańo 21, num.74, julioseptiembre, Universidad de Zulia, pp. 99-110.

, 2019, “¿Hay algo allá afuera? Gravitación del problema althusseriano de la temporalidad en la teoría pecheutiana de los procesos discursivos", Fragmentum, vol. 54, julio-diciembre, 223-258.

2020, "The normalization of barbarism", Crisis and Critique, vol. 7, núm. 3, Lujbiana, noviembre, pp. 259-270.

Ré, Carolina, 2020, "Sobre la temporalidad diferencial o el advenimiento del desajuste", en Carolina Collazo y Natalia Romé (comps.), Asedio del Tiempo. Estudios politicos althusserianos, ClACSO / IIGG, Buenos Aires.

Sader, Emir, 2008, Refundar el Estado. Posneoliberalismo en América Latina, Clacso / Ediciones CTA, Buenos Aires.

Streeck, Wolfgang, 2017, ¿Cómo terminará el capitalismo? Ensayos sobre un sistema en decadencia, José Amoroto, Álvaro García Ormaechea, Juanmari Madariaga y Ethel Odriozola (trad.), Traficantes de sueños, Madrid.

Traverso, Enzo, 2018, Melancolía de izquierda: marxismo, historia y memoria, Horacio Pons (trad.), Fondo de Cultura Económica, Buenos Aires / México.

Wegelin, Lucía, 2017, “El neoliberalismo, ¿racionalidad o ideología? Interrogaciones epistemológicas sobre lo que se cifra en el nombre", presentado en las Jornadas de Sociología, UnCuyo, Mendoza. 